The Polish Journal of the Arts and Culture. New Series 4

(2/2016): 79-87 [ARTYKUะ]

DOI: $10.4467 / 24506249$ PJ.16.011.6242

\title{
Walka kraba z małpą
}

\section{Akutagawa Ryūnosuke tłumaczenie Renata IwICKA}

\section{O autorach}

Akutagawa Ryūnosuke (01.03.1892-24.07.1927), japoński pisarz urodził się jako najstarszy syn Niihary Toshizō i Fuku de domo Akutagawa, jednak jego matka niedługo po urodzeniu syna zaczęła wykazywać objawy choroby umysłowej, zatem chłopca adoptował jej brat, Akutagawa Michiaki. Od najmłodszych lat poznawał kulturę i literaturę rodzimą, chińską, a także europejską, co miało ogromny wpływ na styl jego twórczości, różny od współczesnych mu pisarzy. Cezurą w jego twórczości może być wyjazd do Chin w 1921 roku z ramienia gazety Ōsaka Mainichi Shimbun, który zrujnował i tak słabe zdrowie pisarza. Od tej pory jego obsesją stała się choroba umysłowa, której uległa jego matka, a pragnąc uciec od tego przeznaczenia, w 1927 roku popełnił samobójstwo. W swoich najbardziej znanych utworach jak Kappy, W gąszczu, Życie pewnego szaleńca, czy Rashōmon zastanawiał się nad kondycją istoty ludzkiej oraz współczesnego, modernistycznego i zdehumanizowanego świata.

Renata IwICKA orientalistka i kulturoznawca, adiunkt w Katedrze Porównawczych Studiów Cywilizacji Uniwersytetu Jagiellońskiego. Jej zainteresowania badawcze obejmują historię i kulturę Azji Wschodniej, popkulturę oraz antropologię kultury. Wybrane publikacje: faponia w (pękniętym) lustrze Zachodu wedtug Ryūnosuke Akutagawy, [w:] Spojrzenia. Japonia wedtug Zachodu, Zachód wedtug Japonii, red. A. Wosińska, Toruń, 2013, s. 63-79; Użycie roślin w telewizyjnych serialach fantastycznych, „Maska” 27/2015, s. 159-170; Czy kultura koreańska zatopita Sewol?, [w:] Kultury Wschodu w świecie procesów globalizacyjnych, red. P. Mróz, M. Ruchel, A. I. Wójcik, Kraków, 2015, s. 113-140.

E-MAIL: grad_ecmaise@yahoo.com 


\section{Od tłumaczki}

Historia ${ }^{1}$ walki małpy z krabem (Saru kani gassen) jest znana w Japonii od dawna ${ }^{2}$. Jest to krótka historia kraba, który został oszukany przez małpę znalazł on bowiem na plaży onigiri, kulkę ryżową, będącą jego przysmakiem, ale małpa namówiła go do zamiany jej na słodkie, dojrzałe kaki. Krab się zgodził, jednak małpa wprowadziła go w błąd i ukradła wszystkie dorodne i dojrzałe okazy, w zamian dając mu kwaśny i niedojrzały owoc. Na domiar złego, pobiła go do nieprzytomności. W odwecie upokorzony krab dokonał wraz z towarzyszami zemsty. Historia w tym miejscu się kończy, zostawiając czytelnika, czy też słuchacza, z wrażeniem spełnienia - oto oszukany, słabszy bohater był w stanie zemścić się za doznaną krzywdę. Jest to przykład klasycznej opowieści dydaktycznej, w której zło i fałsz zostają ukarane, a zemsta staje się narzędziem służącym do przekazania prostych prawd moralnych. Oczywisty charakter tej historii został zakwestionowany w 1923 roku za sprawą Akutagawy Ryūnosuke, pisarza, który podjął, z typowym dla swojego stylu sarkazmem, próbę przemodelowania jej schematu.

Akutagawa Ryūnosuke (1892-1927) ${ }^{3}$ tworzył w okresie Taishō (19121926), pozostającym bardzo długo w cieniu dwóch potężnych dziejowo epok: Meiji (1868-1912) oraz Shōwa (1926-1989). Taishō uznawano za okres przej-

${ }^{1}$ Oryginalna historia Saru kani gassen należy raczej do gatunku bajki. Według definicji, jest to krótki utwór literacki zawierający morał, którego bohaterami mogą być ludzie, zjawiska lub zwierzęta (za: Słownik terminów literackich, red. J. Sławiński, Zakład Narodowy im. Ossolińskich, Wrocław 2000, s. 55). Sam Akutagawa używa słowa otogibanashi, nawiązującego do otogizōshi, rodzaju historii ilustrowanych, napisanych, w przeciwieństwie do literatury dworskiej, językiem prostym i zrozumiałym w okresie Muromachi (1333-1573). Zob. J. T. Araki, Otogi-Zoshi and Nara-Ehon: A Field of Study in Flux, „Monumenta Nipponica”, 36 (1/1981), S. 1-20; C. I. Mulhern, Otogi-zōshi. Short Stories of the Muromachi Period, „Monumenta Nipponica”, 29 (2/1974), s. 181-198.

2 Zob. A. Lang, The Crab and the Monkey, [w:] The Crimson Fairy Book, [www 01] (dostęp: 20.05.2016). Historia walki małpy z krabem funkcjonowała przez wieki w rozmaitych wersjach, różniących się między sobą mniej lub bardziej znaczącymi szczegółami (głównie dotyczącymi życia kraba - jego dzieci i towarzyszy, zajęć oraz okoliczności śmierci), co jest cechą charakterystyczną twórczości oralnej (por. W. D. Stempel, Narracja potoczna jako prototyp, „Pamiętnik Literacki”, 81 (1/1990), s. 303-317; W. J. Ong, Oralność i piśmienność. Stowo poddane technologii, tłum. J. Japola, Wydawnictwo Katolickiego Uniwersytetu Lubelskiego, Lublin 1992).

3 Informacje dotyczące życia Akutagawy zob. S. Miyasaka, Akutagawa Ryūnosuke. Hito to sakuhin 芥川龍之介。人と作品 [Akutagawa Ryūnosuke: człowiek i dzieło], Kanrin shobō, Tokyo 2007. 
ściowy, mało interesujący, zupełnie jakby utożsamiono go z postacią chorowitego cesarza Yoshihito. $\mathrm{W}$ ostatnich latach ta ocena zaczyna się $\mathrm{w}$ literaturze przedmiotu zmieniać ${ }^{4}$. Choć krótki, trwający zaledwie czternaście lat, okres ten jest niezwykle inspirujący - już sam slogan epoki mówi wiele o jej charakterze: ero-guro-nansensu, czyli erotyka-groteska-nonsens ${ }^{5}$. Był to czas niepokoju, ideowego fermentu, kiedy Japonia podjęła próbę zaadaptowania zachodnich wzorców demokracji i poniosła porażkę, zwracając się ku militaryzmowi. Istniały wszak partie polityczne, nieznacznie zmodyfikowano prawo wyborcze, rozwijało się życie artystyczne i towarzyskie. $Z$ tego też względu do epoki przylgnęło określenie „demokracji Taishō”. Działała jednak cenzura, czego echo można odnaleźć w Kappach ${ }^{6}$, gdzie ocenzurowano wiele sfer działalności artystycznej, na przykład instrumentalny utwór muzyczny. To epoka wewnętrznych sprzeczności, wymieszania wartości tradycyjnych z modernistycznym pędem (do czego?) elit intelektualnych i artystycznych, której wewnętrzna cezura przypada na rok 1923 - rok wielkiego trzęsienia ziemi w Kantō, które pochłonęło ponad sto tysięcy istnień ludzkich i zniszczyło Tokio. Rok ten oznacza również początek powolnego upadku względnej wolności artystycznej, ideowej i osobistej. Nie jest zatem niczym dziwnym, że w tym samym roku powstało opowiadanie, które zrujnowało iluzję szczęśliwego zakończenia, ułudę dobrobytu i spokoju.

Akutagawa często sięgał po tradycję literacką zarówno swojego kraju, jak i innych regionów. $Z$ tego powodu część krytyków podnosiła wobec jego twórczości zarzut nieoryginalności i epigoństwa. Motywy zaczerpnięte z dawnej kultury, zarówno ludowej, jak i dworskiej, noszą jednak wyraźny ślad współczesności i zeuropeizowania - jest to proza ustrukturyzowana, przejrzysta, psychologizująca. Pisarz nie stronił od groteski. Stanowiła ona jeden z kluczowych elementów jego twórczości, a świat przedstawiony w jego krótkich opowiadaniach (nigdy nie napisał powieści) bardzo często jest światem karykatury, obrazem współczesnej mu Japonii w zwierciadle, które po-

4 Por. B. S. Silberman, H. D. Harootunian, G. L. Bernstein, Japan in Crisis: Essays on Taishō Democracy, University of Michigan, Ann Arbor 1999 [1974]; S. Minichello, Japan's Competing Modernities: Issues in Culture and Democracy, 1900-1930, University of Hawaii Press, Honolulu 1998; S. Lippit, Topographies of Japanese Modernism, Columbia University Press, New York 2002; E. K. Tipton, Faces of New Tokyo: Entertainment Districts and Everyday Life during the Interwar Years, „Japanese Studies”, 33 (2/2013), s. 185-200.

5 Por. R. Hutchinson, Negotiating Censorship in Modern Fapan, Routledge, New York 2013.

${ }^{6} \mathrm{~W}$ polskim przekładzie jako W krainie wodników (Życie pewnego szaleńca), tłum. M. Melanowicz. 
kazywało bardzo niepochlebny obraz. Walka kraba z małpa to utwór bardzo krótki, wypełniony po brzegi zjadliwą krytyką funkcjonowania społeczeństwa japońskiego, choć nie jest to jedyny klucz do zrozumienia tego opowiadania. Na płaszczyźnie fabularnej usłyszeć można echa starć ideologicznych - socjalistycznych, nacjonalistycznych, kapitalistycznych, religijnych, a nawet anarchistycznych. Pojawia się krytyka systemu sądownictwa (adwokat), kontaktów handlowych (dowody transakcji), intelektualistów, brukowych magazynów goniących za sensacją, a nawet środowiska pisarzy, choć tutaj ostrze ironii wymierzone jest być może w konkretną postać - Tanizakiego Jun’ichirō, który znany był z licznych kontaktów z pięknymi kobietami ${ }^{7}$. Język opowiadania jest zwodniczo lekki, rzeczowy, użyty w bardzo precyzyjny sposób, dzięki czemu wykreowany zostaje świat, wobec którego zdystansowany jest zarówno pisarz, jak i czytelnik, z wyjątkiem kilku zdań zaburzających ów chłodny opis. Sytuacja taka występuje, kiedy Akutagawa bądź to zwraca się bezpośrednio do czytelników, bądź też powołuje się na nich, uzasadniając swoją decyzję opisania prawdziwych losów grupy mścicieli. Konkluzja opowiadania jest ponura - czytelnicy porównani są do krabów, których system poświęci dla dobra ogółu. Można się zastanowić, ile szczegółów tego krótkiego utworu jest nadal aktualnych w XXI wieku.

\section{Walka kraba z małpą}

Krab, któremu małpa ukradła onigiri, wreszcie dokonał zemsty. Z pomocą kamienia młyńskiego, pszczoły i jajka zabił swego zaprzysięgłego wroga. Nie ma potrzeby powtarzać całej historii. Powinno się zaś przeanalizować losy całej grupy, począwszy od kraba, po tym, jak dokonano morderstwa. Niby dlaczego powinno? Ano dlatego, że legenda nic o tym nie wspomina.

Nie dość, że nic o tym nie wspomina, to jeszcze można odnieść wrażenie, że cała grupa spędziła resztę życia w spokoju i bezpieczeństwie: krab w swojej norce, kamień w kącie kuchni, pszczoła w ulu u powały dachu, a jajko w skrzynce z plewami.

Ale to nieprawda. Po dokonaniu zemsty wszyscy zostali schwytani przez policję i wtrąceni do więzienia. Na mocy licznych werdyktów sądowych prowodyr zbrodni - krab - został skazany na karę śmierci, a jego wspólnicy:

7 Por. D. Keene, Dawn to the West: Japanese Literature of the Modern Era, Volume 3: Fiction, Columbia University Press, New York 1998. 
kamień, pszczoła i jajko, usłyszeli wyroki dożywocia. Ci z czytelników, którzy znają tylko wersję bajki, mogą mieć wątpliwości co do losów tej grupy. Jednak to fakt. Niezaprzeczalny fakt.

Według zeznań kraba najpierw doszło do wymiany onigiri na kaki między nim a małpą. Jednak małpa nie dość, że nie przyniosła dojrzałego owocu, podmieniając go na niedojrzały, to jeszcze cisnęła nim w kraba - jak wyznał z zamiarem cielesnego uszkodzenia. Niestety, krab nie posiadał ani skrawka paragonu potwierdzającego transakcję. Nawet gdyby zignorować ten brak, krab nie był w stanie potwierdzić faktów dotyczących stopnia dojrzałości kaki użytej podczas procesu wymiany. I wreszcie, nie ma wystarczających dowodów, by uznać akt ciśnięcia niedojrzałą kaki w kraba za przejaw złośliwości ze strony małpy. $Z$ tego też względu nawet obrońca kraba, adwokat Jakiśtam $^{1}$, znany ze swej elokwencji, nie miał innej linii obrony, jak tylko apelować do sędziego o współczucie. Świadkowie mówili, że litościwie ocierał pot z czoła kraba, powtarzając mu, by się poddał. Nikt nie jest w stanie ustalić, czy owo „poddaj się” dotyczyło akceptacji kary śmierci, czy też astronomicznego rachunku za usługi adwokackie.

Dodatkowo, jak utrzymuje prasa, opinia publiczna była niemal w całości przeciwko krabowi. Większość uważała, że krab zamordował małpę z powodu osobistej urazy. A skoro już mowa o osobistej urazie prowadzącej do tej tragedii, to czyż nie była ona jedynie wynikiem krabiej ignorancji i bezmyślności, co małpa tylko z zyskiem wykorzystała? Ktoś musi być głupcem lub szaleńcem, by dać się ponieść osobistym urazom w świecie rządzonym prawem dżungli. Baron Jakiśtam, szef Komisji Handlowej, podzielał powyższą opinię, dodając ponadto, że czyn kraba mógł być związany z różnymi modnymi podówczas wywrotowymi i niebezpiecznymi ideami ${ }^{2}$. Ta konkluzja pchnęła barona do zatrudnienia ochrony i zaopatrzenia się w dziesięć buldogów.

Czyn kraba nie przysporzył mu popularności nawet wśród tak zwanej inteligencji. Profesor Jakiśtam stwierdził, że ponieważ czyn kraba wynikał z pragnienia zemsty, z punktu widzenia filozofii moralnej trudno uznać go za chwalebny. Co więcej, jeden z prominentnych socjalistów uznał, że ponieważ krab cenił własność prywatną (jak onigiri czy też kaki), to można przyjąć, że kamień, pszczoła i jajko również sympatyzowali z podobnie reakcyjnymi myślami, a tak w ogóle całe wydarzenie to zapewne spisek prawicy.

1 W oryginale Akutagawa używa znaku na określenie „pewien”, „jakiś”.

${ }^{2}$ Chodzi o ruchy socjalistyczne. 
Dodatkowo pewien opat jednej z buddyjskich szkół uznał, że cała afera to wynik krabiej nieznajomości buddyjskiej idei współczucia. Gdyby bowiem wiedział o tym cokolwiek, to nawet gdyby został uderzony niedojrzałą kaki, zamiast ulegać złości, okazałby litość. Wyraził ubolewanie, że krab nie miał okazji wysłuchać któregoś z jego kazań na temat współczucia. Wielu różnych ludzi, w tym bardzo znanych, jednogłośnie krytykowało i potępiało kraba. Tylko jedna osoba zdawała się stać po jego stronie - był to pewien parlamentarzysta, alkoholik i poeta. Oznajmił on, że zachowanie kraba było zgodne z regułami bushidō ${ }^{3}$. Jednak taki przestarzały argument do nikogo nie trafiał. Plotkarskie magazyny podały, że ten sam parlamentarzysta kilka lat wcześniej został obsikany w zoo przez pewną małpę, więc najpewniej dlatego żywił do nich urazę.

Czytelnicy, którzy znają tylko bajkę, zapewne uronią łzę nad smutnym losem kraba. Jednak jego śmierć jest tylko naturalna. Jedynie sentymentalizm kobiet i dzieci może prowadzić do użalania się nad nim. Świat ocenił śmierć kraba jako uzasadnioną. Kiedy wykonano na nim wyrok, sędzia, prokurator, adwokat, dozorca więzienia, kat, a także kapelan spali snem sprawiedliwych przez czterdzieści osiem godzin. Co więcej, wszyscy później przekazali, że śnili o wrotach do raju. Według nich raj wyglądał jak wielki dom handlowy zbudowany na wzór feudalnego zamku.

Należy w tym miejscu dopisać, co stało się z rodziną kraba po jego śmierci. Jego żona została prostytutką. Jaki był tego motyw - czy bieda, czy też naturalne inklinacje - do dziś pozostaje niejasne. Najstarszy syn po śmierci ojca - jak to wyraził pewien dziennikarz - „nagle zmienił swoje życie” i został księgowym na giełdzie, czy coś w tym stylu. Pewnego razu zawlókł on rannego towarzysza do swej jamki, zapewne w celu konsumpcji współplemieńca. Jego postać została użyta przez Kropotkina ${ }^{4}$ w traktacie o pomocy wzajemnej jako przykład pomocy wewnątrz grupy współplemieńców. Drugi syn został pisarzem. Zachowywał się, jak przystało na typowego pisarza, i prócz namiętności do kobiet nie odznaczał się niczym szczególnym. Nawiązując do życia ojca, wygłaszał nieprzemyślane, ironiczne zdania, takie jak:

3 Dosłownie oznacza „drogę wojownika”, nawiązuje do kodeksów rycerstwa japońskiego w epoce feudalnej, a także znanej historii o zemście czterdziestu siedmiu rōninów za śmierć pana.

4 Piotr Aleksiejewicz Kropotkin (1842-1921) - geograf, filozof, jeden z najwybitniejszych teoretyków anarchizmu komunistycznego. W 1902 roku wydał traktat Pomoc wzajemna, o którym wspomina Akutagawa. Zob. G. Woodcock, Kropotkin, Peter (1842-1921), [w:] The Encyclopedia of Philosophy, red. P. Edwards, [www 02] (dostęp: 20.05.2016). 
„dobro to tylko inna nazwa zła”. Najmłodszy syn był półgłówkiem i dlatego nie miał dążeń innych niż typowo krabie. Pewnego dnia szedł sobie po krabiemu i napotkał kulkę onigiri. Było to jego ulubione danie. Podniósł więc owo cudo swymi potężnymi szczypcami. Tak się złożyło, że na czubku pobliskiego drzewa siedziała małpa, iskając sobie pchły... Nie ma potrzeby dodawać, co z tego wynikło.

Tak czy inaczej, faktem pozostaje, że rezultat walki kraba z małpą zawsze będzie taki sam. Krab zostanie zabity dla dobra społeczeństwa. To przedkładam czytelnikom na całym świecie. Jesteście krabami! 


\section{Bibliografia}

\section{Teksty źródłowe:}

1. Akutagawa R. 芥川龍之介, Saru kani gassen 猿蟹合戦 [Walka matpy z krabem], [www 03] (dostęp: 7.03.2016).

\section{Opracowania:}

2. Akutagawa R. 芥川龍之介, Kappa, 河童 [W krainie wodników], [w:] Życie pewnego szaleńca, tłum. M. Melanowicz, Dialog, Warszawa 1998.

3. Araki J. T., Otogi-Zoshi and Nara-Ehon: A Field of Study in Flux, „Monumenta Nipponica", 36 (1/1981), s. 1-20.

4. Hutchinson R., Negotiating Censorship in Modern Japan, Routledge, New York 2013.

5. Keene D., Dawn to the West: Japanese Literature of the Modern Era, Volume 3: Fiction, Columbia University Press, New York 1998.

6. LANG A., The Crab and the Monkey [w:] The Crimson Fairy Book, [www o1] (dostęp: 20.05.2016).

7. LIPPIT S., Topographies of Japanese Modernism, Columbia University Press, New York 2002.

8. Minichello S., Japan's Competing Modernities: Issues in Culture and Democracy, 1900-1930, University of Hawaii Press, Honolulu 1998.

9. Miyasaka S. 宮坂覺, Akutagawa Ryūnosuke. Hito to sakuhin 芥川龍之介。 人と作品 [Akutagawa Ryūnosuke: człowiek i dzieto], Kanrin shobō, Tokyo 2007.

10. Mulhern C. I., Otogi-zōshi. Short Stories of the Muromachi Period, „Monumenta Nipponica", 29 (2/1974), s. 181-198.

11. Ong W. J., Oralność i piśmienność. Stowo poddane technologii, tłum. J. Japola, Wydawnictwo Katolickiego Uniwersytetu Lubelskiego, Lublin 1992.

12. Silberman B. S., Harootunian H. D., Bernstein G. L., Japan in Crisis: Essays on Taishō Democracy, University of Michigan, Ann Arbor 1999 [1974].

13. Słownik terminów literackich, red. J. Sławiński, Zakład Narodowy im. Ossolińskich, Wrocław 2000.

14. Stempel W. D., Narracja potoczna jako prototyp, „Pamiętnik Literacki”, 81 (1/1990), s. 303-317. 
15. Tipton E. K., Faces of New Tokyo: Entertainment Districts and Everyday Life during the Interwar Years, ,Japanese Studies”, 33 (2/2013), s. 185200.

16. Woodcock G., Kropotkin, Peter (1842-1921) [w:] The Encyclopedia of Philosophy, red. P. Edwards, [www 02] (dostęp: 20.05.2016).

\section{Wykorzystane źródła internetowe:}

[www 01] http://www.classicreader.com/book/971/30/

[www 02] http://www.ditext.com/woodcock/kropotkin.html

[www 03] http://www.aozora.gr.jp/cards/ooo879/card140.html 